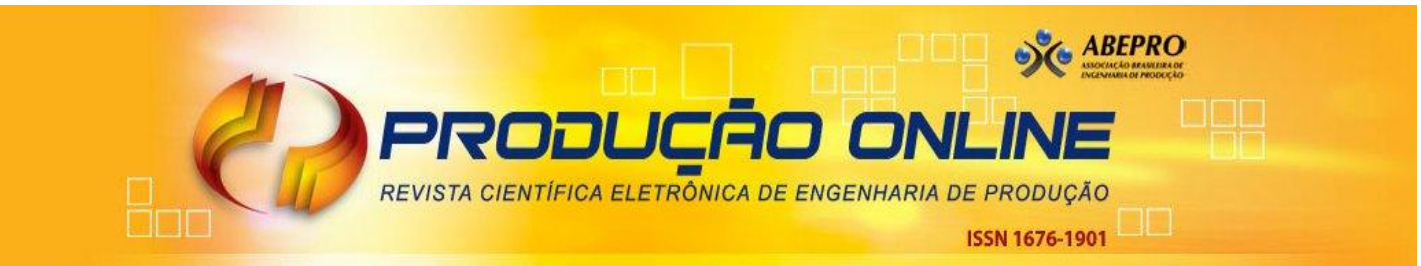

\title{
INDICADORES DE DESEMPENHO, PRÁTICAS E CUSTOS DA MANUTENÇÃO NA GESTÃO DE PNEUS DE UMA EMPRESA DE TRANSPORTES
}

\section{PERFORMANCE INDICATORS, PRACTICES AND MAINTENANCE COSTS IN TIRES MANAGEMENT OF A TRANSPORT COMPANY}

\author{
Marcos Dario *E-mail: dariomarcos2008@yahoo.com.br \\ Eliciane Maria da Silva** E-mail: eliciane.silva@fgv.br \\ Mário Sacomano Netto** E-mail: msacomano@ufscar.br \\ Sílvio Roberto Ignacio Pires*E-mail: sripires@unimep.br \\ * Universidade Metodista de Piracicaba (UNIMEP), Piracicaba, SP \\ ** Fundação Getúlio Vargas - Escola de Administração de Empresas de São Paulo \\ (FGV/EAESP), São Paulo, SP \\ ${ }^{* * *}$ Universidade Federal de São Carlos (UFSCAR), São Carlos, SP
}

\begin{abstract}
Resumo: Existem três custos operacionais expressivos para os prestadores de serviços logísticos (PSL): manutenção dos veículos, dos pneus e o abastecimento de combustível. Nos estudos de manutenção pouco se tem pesquisado sobre o conceito da gestão de pneus, técnicas de manutenção e desempenho conjuntamente. Nesse contexto, este estudo tem como objetivo identificar as práticas e indicadores de desempenho da área da manutenção na gestão de pneus e também, analisar a influencia dos custos aplicados aos pneus sobre o custo total da manutenção. Do ponto de vista metodológico, foi realizado um estudo de caso exploratório, descritivo e analítico. Os principais instrumentos de coleta de dados foram à observação in loco, entrevista não estruturada, análise de documentos e de relatórios com resultados de indicadores. Os dados foram analisados pela análise de correlação e regressão múltipla. Foi revelado que dentre os indicadores de desempenho da manutenção na gestão de pneus, os custos aplicados aos pneus possuem maior correlação com o custo total da manutenção. O teste Anova indicou que os custos aplicados aos pneus influenciam em $54 \%$ das variações no custo total da manutenção. Foram esclarecidos os conceitos sobre técnicas de manutenção específicas da gestão de pneus, além de identificar os indicadores de desempenho na área de gestão de pneus.
\end{abstract}

Palavras-chave: Prestador de Serviços Logísticos (PSL). Manutenção. Gestão de pneus. Desempenho operacional.

Abstract: There are three operational costs that are more expressive for PSL: vehicle maintenance, tires and fuel. In studies of maintenance has been little researched the concept of tire management, technical maintenance and performance together. In this context, this study aims at identifying the practices and performance indicators in the area of maintenance and tire management also analyze the influence of costs applied to the tires on the total cost of maintenance. We conducted a case study of exploratory and descriptive. The main instruments of data collection were on-site observation, unstructured interviews, document analysis and reports results indicators. Data were analyzed by correlation analysis and multiple regression. It was revealed that among the performance indicators in the management of tire maintenance costs applied to the tires have a higher correlation with the total cost of maintenance. The

Revista Produção Online, Florianópolis, SC, v.14, n. 4, p.1235-1269, out./dez. 2014. 
ANOVA indicated that tire maintenance costs influence in $54 \%$ of the variations in the total cost of maintenance. We clarified the concepts of maintenance techniques specific tire management, and identify performance indicators in the area of tire managent.

Keywords: Logistic Service Provider (LSP). Maintenance. Tire management. Operational performance.

\section{INTRODUÇÃO}

Uma das importantes funções exercidas por operadores logísticos na cadeia de suprimentos é a gestão das atividades de transportes e armazenagens (VIVALDINI E PIRES, 2010; BALLOU, 2001; FLEURY, 2002; NOVAES, 2002; LAMBERT et al., 1996). Então, um dos elementos centrais para o desempenho dos operadores logísticos relaciona-se com os resultados e a eficiência na gestão e manutenção da frota. Assim, observa-se um crescimento do interesse da comunidade acadêmica e empresarial sobre a relação entre manutenção e desempenho (PERES e LIMA, 2008; AMBRÓSIO e LEITE, 2008, NARAYAN, 2012; SULTANA, RAHMAN e CHOWDHURY, 2013). Mas poucos estudos são voltados especificamente para o estudo da manutenção da frota e os impactos nos custos.

O tema envolvendo práticas e os indicadores da gestão de manutenção de pneus se justifica pela importância da logística no transporte de cargas pelo sistema rodoviário e o crescente número de operadores logísticos no Brasil. Tal sistema é o principal meio de transportes no país e desempenha um papel vital para a economia. $O$ sistema rodoviário é responsável pelo escoamento dos produtos transportados, que giram em torno de $7,5 \%$ do PIB (Produto Interno Bruto), representando, segundo a Confederação Nacional de Transportes - CNT (2013), $1.713 .885 \mathrm{~km}$ de rodovias, das quais apenas $202.589 \mathrm{~km}$ são pavimentados, isto é, 11,8\% da malha. Entre as rodovias pavimentadas, $64.921 \mathrm{~km}$ são federais. Destes, apenas 8\% são de pista dupla (5.203 km), e 2,1\% (1.376 km) são vias em fase de duplicação; os demais 89,9\% são de pista simples. Com uma frota de 2.060 .002 veículos de transportes (caminhões e ônibus), envolvendo cerca de 188.613 empresas, que representa o transporte de 485.625 milhões de toneladas transportadas, com $61,1 \%$ de participação desse modal no transporte total de cargas, contanto ainda com 1.008 .758 autônomos, com $14.621 \mathrm{~km}$ 
de concessão de malha rodoviária privada e $1.195 \mathrm{~km}$ administrados por operadores estaduais (DARIO, 2012).

Nesse sentido, os custos de manutenção ganham importância significativa para a competitividade das empresas (AMBRÓSIO e LEITE, 2008; TOPAL e RAMAZAN, 2010) e na gestão da frota para operadores logísticos.

Basicamente, existem três custos operacionais que são mais expressivos para um prestador de serviços logístico: manutenção dos veículos, pneus e combustível (DARIO, 2012). Se a empresa mantiver o veículo em boa manutenção e com um bom condutor é possível que haja economias. Segundo o Sindicato das Empresas de Transportes de Cargas do Estado de São Paulo - SETCESP (2009), veículos de cinco anos de vida útil, com média de rodagem de $10.000 \mathrm{~km}$ por mês, gastam na média em: a) manutenção $10 \%$, b) pneus $8 \%$, c) combustíveis $35 \%$, d) óleo lubrificantes $3 \%$, e) lavagem e lubrificação $4 \%$, f) custos fixos da administração do veículo $40 \%$, totalizando os $100 \%$ dos custos fixos e variáveis.

A interferência que cada um desses custos apresenta, está diretamente relacionada ao modo como o motorista conduz o veículo e as características das operações deste transporte. É por isso que, quanto mais adequadamente o veiculo for conduzido e as operações de manutenção realizadas de forma mais eficazes, menor será o custo operacional (DARIO, 2012).

Então, as práticas de gestão de manutenção na gestão de pneus representam um investimento muito valioso e na falta destes poderá ocorrer um elevado custo para os operadores logísticos, tais como: a) consumo excessivo de peças e pneus; b) excesso de mão de obra de oficina; c) maior tempo do veiculo parado; d) diminuição da vida útil do veículo e de pneus, e) aumento dos custos, f) diminuição da receita e f) perda de clientes. Entretanto, nos estudos de manutenção pouco se tem pesquisado sobre 0 conceito da gestão de pneus, com as técnicas de manutenção, bem como a sua relação com o desempenho (DARIO, 2012).

Por exemplo, alguns estudos atentam-se para a relação entre manutenção, desempenho e custos. Oliveira (2005), fez uma análise crítica dos requisitos de segurança e desempenho de pneus automotivos. Já Loch (2007), abordou a 
necessidade de conhecer a gestão de manutenção de veículos pesados, com a colaboração de membros de uma empresa logística. Haviaras (2005), desenvolveu uma metodologia para análise de confiabilidade de pneus radiais em frota de caminhões de longa distância. Portanto, a problematização desta pesquisa diz respeito às necessidades e às carências empresariais quanto ao tema gestão de pneus, como também, às lacunas teóricas dos estudos de manutenção relativos a estes três temas conjuntamente: manutenção, gestão de pneus e desempenho operacional, aplicados as empresas de transportes. Assim, foram formuladas as seguintes questões de pesquisa: (Q1) Quais práticas da manutenção representam o conceito de manutenção na gestão de pneus? (Q2) Quais são os indicadores de desempenho operacionais da manutenção na gestão de pneus? (Q3) Quais medidas da área de manutenção na gestão de pneus estão associadas significativamente aos desempenhos de custos pneus? (Q4) Os custos aplicados aos pneus influenciam significativamente o custo total de manutenção? Portanto, este estudo teve o objetivo de identificar as práticas e indicadores de desempenho da área de manutenção na gestão de pneus. Também, buscou-se analisar a influência dos custos aplicados aos pneus sobre o custo total da manutenção. Já como objetivos específicos foram pesquisados os indicadores da gestão de manutenção e pneus e, as suas práticas; identificados os indicadores de desempenho operacionais da manutenção na gestão de pneus; identificadas como as medidas da área de manutenção na gestão de pneus estão associadas aos desempenhos de custos de pneus e por fim, investigada a relação entre os custos aplicados aos pneus sobre o custo total de manutenção.

$\mathrm{Na}$ sequência desta introdução é apresentada a revisão da literatura sobre os conceitos de gestão de frota, manutenção e medidas de desempenho aplicadas aos custos dos pneus. Posteriormente, são descritos os procedimentos metodológicos para a execução da pesquisa empírica, desenvolvidos os resultados e as análises dos dados coletados e, por fim, são apresentadas as considerações finais deste estudo. 


\section{GESTÃO DE FROTAS E MANUTENÇAO}

A relação entre manutenção e desempenho tem recebido foco em diversos estudos (PERES e LIMA, 2008; AMBRÓSIO e LEITE, 2008, NARAYAN, 2012; SULTANA, RAHMAN e CHOWDHURY, 2013). Particularmente, os operadores logísticos têm custos de manutenção elevados no gerenciamento da frota.

Ademais, as empresas que possuem frota própria, sofrem muitas dificuldades por outros diversos fatores, tais como: a) alto investimento em renovação de frota, b) condições de segurança nas estradas, c) falta de um planejamento melhor por partes dos órgãos governamentais, d) falta de investimentos em infra-estrutura logística estratégica para armazenagem, distribuição, exportação e importação, entre outros (VALENTE, 1994 e CLEMENTE, 2008).

O Brasil tem forte vocação do sistema rodoviário no transporte de cargas (serviços de entregas porta a porta), sendo esta uma das razões importantes para uma implantação de uma boa gestão de frotas nas empresas, conforme já comentado na introdução. Nesse sentido, são esperados alguns benefícios de uma boa gestão de frotas como: redução de custo, melhor qualidade e desempenho de serviços, maior controle de peças e componentes, aumento das médias de combustíveis, melhor gestão de manutenção e pneus, entre outros.

Segundo Valente et al. (2003), a gestão de frotas engloba atividades como: a) gerenciar, b) comandar, c) administrar, e d) planejar as atividades de um conjunto de veículos pertencentes a uma mesma empresa. Para o gestor de transportes há exigência de um amplo conhecimento de tarefas e questões abrangentes, como: a) saber, sobre a previsão e controle dos custos operacionais, b) planejar a manutenção, c) controlar as necessidades de renovação da frota, d) dimensionar a frota, e) especificar e avaliar veículos e equipamentos, f) comprometer-se com os colaboradores, g) operar a frota, e h) acomodar as cargas e i) inovações tecnológicas. Atualmente as organizações vêm buscando novas ferramentas de gerenciamento, que proporcione a uma maior competitividade através da qualidade e da produtividade de seus serviços, para isso acontecer às empresas necessitam que os diversos setores 
apresentem os melhores resultados na busca pela excelência. Por sua vez, a manutenção é a responsável pela disponibilidade dos ativos, sendo o mais importante nos resultados de custos das empresas e no aumento da produção.

Para Kardech e Nascif (2013), o custo de manutenção no Brasil por faturamento bruto das empresas é de 4,11\% na média entre 1995 a 2011, apesar de ser importante continuar reduzindo custo de manutenção, é preciso dar prioridade ao aumento de disponibilidade e da confiabilidade, já que estes fatores estão ligados ao faturamento e representam 95,8\% da equação faturamento / custo das empresas. Os mesmos autores citam ainda que nos últimos anos a atividade de manutenção tem passado por muitas mudanças, estas mudanças são consequências de: a) aumento do número e da diversidade dos itens físicos (edificações, equipamentos, instalações), b) aumento da automação, instrumentação e monitoramento dos equipamentos, c) projetos mais amplos, d) novas técnicas de manutenção, e) novos ensinamentos sobre a organização da manutenção e suas responsabilidades, f) importância da função manutenção como função estratégica para a melhoria de resultados e também para o aumento da competitividade das empresas, g) introdução da gestão como fator indispensável para alcançar os melhores resultados para a manutenção e para a organização como um todo.

A evolução da manutenção surgiu a partir de 1930, e a partir, pode ser dividida em cinco gerações, mostradas na Tabela 1. 
Tabela 1 - Evolução da manutenção

\begin{tabular}{|c|c|c|c|c|c|}
\hline Geração & $\begin{array}{l}\text { Primeira } \\
\text { Geração }\end{array}$ & $\begin{array}{l}\text { Segunda } \\
\text { Geração }\end{array}$ & $\begin{array}{l}\text { Iolução da manute } \\
\text { Terceira } \\
\text { Geração }\end{array}$ & $\begin{array}{l}\text { ão } \\
\text { Quarta Geração }\end{array}$ & Quinta geração \\
\hline Ano & 1930 a 1950 & 1960 a 1970 & 1980 a 1990 & 2000 a 2005 & 2010 a 2015 \\
\hline $\begin{array}{l}\text { Expectativa x } \\
\text { relação } \\
\text { manutenção }\end{array}$ & $\begin{array}{l}\text { Conserto após } \\
\text { falha. }\end{array}$ & $\begin{array}{l}\text { Disponibilidade } \\
\text { Maior vida útil de } \\
\text { equipamento. }\end{array}$ & $\begin{array}{l}\text { Confiabilidade; } \\
\text { Melhor redução } \\
\text { custo benefício; } \\
\text { Preservação do } \\
\text { meio ambiente. }\end{array}$ & $\begin{array}{l}\text { Segurança; } \\
\text { Gerenciar ativos; } \\
\text { Influir nos } \\
\text { resultados dos } \\
\text { negócios. }\end{array}$ & $\begin{array}{l}\text { Gerenciar os ativos; } \\
\text { Otimizar os ciclos dos } \\
\text { ativos; } \\
\text { Influir nos resultados } \\
\text { do negócio. }\end{array}$ \\
\hline $\begin{array}{l}\text { Visão quanto } \\
\text { a falha do } \\
\text { ativo. }\end{array}$ & $\begin{array}{l}\text { Equipamentos } \\
\text { se desgastam } \\
\text { com a idade e } \\
\text { por isso falham. }\end{array}$ & $\begin{array}{l}\text { Equipamentos se } \\
\text { comportam de } \\
\text { acordo com a } \\
\text { curva da } \\
\text { banheira. }\end{array}$ & $\begin{array}{l}\text { Existência de } \\
\text { seis padrões de } \\
\text { falhas }\end{array}$ & $\begin{array}{l}\text { Reduzir falhas } \\
\text { prematuras }\end{array}$ & $\begin{array}{l}\text { Planejamento do ciclo } \\
\text { de vida desde o } \\
\text { projeto para reduzir as } \\
\text { falhas. }\end{array}$ \\
\hline $\begin{array}{l}\text { Mudanças } \\
\text { nas técnicas } \\
\text { de } \\
\text { manutenção }\end{array}$ & $\begin{array}{l}\text { Habilidades } \\
\text { para o reparo }\end{array}$ & $\begin{array}{l}\text { Planejamento } \\
\text { manual da } \\
\text { manutenção; } \\
\text { Computadores } \\
\text { lentos; } \\
\text { Manutenção } \\
\text { preventiva por } \\
\text { tempo. }\end{array}$ & $\begin{array}{l}\text { Monitoramento; } \\
\text { Manutenção } \\
\text { preditiva; } \\
\text { Análise de risco; } \\
\text { Computadores } \\
\text { rápidos; } \\
\text { Softwares } \\
\text { potentes; grupos } \\
\text { de trabalho } \\
\text { disciplinares; } \\
\text { Projetos voltados } \\
\text { para a } \\
\text { confiabilidade. }\end{array}$ & $\begin{array}{l}\text { Aumento da } \\
\text { manutenção } \\
\text { preditiva e } \\
\text { monitoramento; } \\
\text { Redução nas } \\
\text { manutenções } \\
\text { preventiva e } \\
\text { corretiva não } \\
\text { planejada; } \\
\text { Análise de falhas; } \\
\text { técnicas de } \\
\text { confiabilidade; } \\
\text { Manutenibilidade; } \\
\text { Projetos voltados } \\
\text { para a } \\
\text { confiabilidade, } \\
\text { manutenibilidade e } \\
\text { disponibilidade; } \\
\text { Contratação por } \\
\text { resultados. }\end{array}$ & $\begin{array}{l}\text { Aumento da } \\
\text { manutenção preditiva } \\
\text { e monitoramento; } \\
\text { Participação efetiva no } \\
\text { projeto, aquisição, } \\
\text { instalação, } \\
\text { comissionamento, } \\
\text { operação e } \\
\text { manutenção dos } \\
\text { ativos; } \\
\text { Garantir que os ativos } \\
\text { operem dentro da sua } \\
\text { máxima eficiência; } \\
\text { Implementar } \\
\text { melhorias, objetivando } \\
\text { a redução de falhas; } \\
\text { Excelência em } \\
\text { engenharia de } \\
\text { manutenção; } \\
\text { Consolidação das } \\
\text { melhorias por } \\
\text { resultados. }\end{array}$ \\
\hline
\end{tabular}

Fonte: Kardech e Nascif (2013).

Melhores práticas da manutenção, segundo Kardech e Nascif (2013), são aquelas que se têm mostrado superiores em resultados, selecionados por um processo sistemático e julgadas como exemplares, boas ou de sucesso demonstrado.

De um modo geral as ferramentas implantadas nas empresas de classe mundial, como maior sucesso foram: a) Gestão da Qualidade Total, b) Gerencia de Rotina, c) Padronização, d) 5S, e) TPM, f) Benchmarking, g) BSC, h) Gestão de Ativos, além disto é claro a certificação em relação as normas internacionais, que levam as empresas a melhorarem sua gestão alcançando melhores resultados como as ISO 9001, ISO 14001, OSHAS 18001 e PAS 55000 (KARDECH E NASCIF, 2013).

Para otimizar a organização como um todo, várias ferramentas estão disponíveis, mas elas só darão resultados eficazes à medida que o pessoal da manutenção 
internalizar uma nova cultura, sua missão estratégica, seus novos paradigmas, os tipos mais eficazes de manutenção, a pratica do trabalho em equipe, a multifuncionalidade ou polivalência, a manutenção deve intervir de forma planejada na organização.

Atualmente são definidos seis tipos básicos de manutenção: 1) Corretiva não planejada, 2) Corretiva planejada, 3) Preventiva, 4) Preditiva, 5) Detectiva, 6) Engenharia de Manutenção.

Os resultados para a manutenção que aplica as melhores práticas atualmente, incluem:

- $100 \%$ da confiabilidade requerida são atingidos $100 \%$ do tempo;

- Falta de sobressalentes no estoque é rara (menos que 1 por mês);

- Horas extras não passam de $2 \%$ em relação ao tempo total de manutenção;

- $100 \%$ do tempo dos executantes cobertos por ordens de serviço;

- $90 \%$ do comprimento de programação de serviços;

- Os custos de manutenção são de $2 \%$ do orçamento.

Esses resultados não se atingem sem a aplicação das melhores práticas. Precisa haver para a aplicação e implementação o envolvimento de todos os colaboradores da organização, além disso para que os resultados sejam alcançados, é necessário:

- Comprometimento de toda a estrutura organizacional;

- Perseverança ou constância dos propósitos;

- Que o programa independa das pessoas, ou seja, deve ser sistematizado e se constituir em um programa da organização.

Ferramentas de manutenção utilizadas para o aumento da confiabilidade nas empresas de classe mundial, podemos destacar:

- Análise do Modo e Efeito de Falha - FMEA (é uma abordagem que ajuda a identificar e priorizar as falhas potenciais em equipamentos, sistemas ou processos);

- Análise de Causa-Raiz de Falha - RCFA (é um método ordenado de buscar as causas de problemas e determinar as ações apropriadas para evitar a reincidência); 
- Método de análise de problemas - MASP (é uma sistemática de análise e solução de problemas adotadas na Gestão da Qualidade Total);

- Manutenção Centrada na Confiabilidade - RCM (é um processo usado para determinar os requisitos de uma manutenção de qualquer item físico no seu contexto operacional).

\subsection{A gestão de manutenção e medidas de desempenho aplicadas aos custos dos pneus}

Os custos dos pneus é um dos mais críticos, em termos de manutenção, conservação, aquisição e controle, pois depende de várias variáveis como: as condições das estradas, armazenagens, preço dos pneus, perdas de pneus durante as operações de transportes, roubos e acidentes. De acordo com a Associação Nacional da Industria de Pneumáticos - ANIP (2014) e FUNDAÇÃO ADOLPHO BÓSIO DE EDUCAÇÃO NO TRANSPORTE - FABET, (2010) a vida útil dos pneus depende de uma manutenção cuidadosa por parte do motorista, nesta área, ela orienta sobre o limite de segurança, pressão, o rodízio de pneus e dicas importantes para evitar o desgaste do pneu.

Para Kato (2005), investimentos significativos têm que ser realizados para a manutenção e pneus como, por exemplo: estoques de reposição, alinhamento e balanceamento, ressolagens, consertos, o que mostra a necessidade de um controle e gerenciamento para minimizar o impacto nos custos das empresas.

O pneu é um dos itens mais importante do veículo e na manutenção (ANIP, 2014), porque: (a) o pneu é que está na ponta final de uma série de sistemas mecânicos do veículo; (b) é um dos custos mais altos das empresas; (c) é um componente que merece cuidado por parte dos motoristas, pois são eles que ficam o maior tempo com o veiculo; (d) o pneu depende de acompanhamento que trazem resultados positivos em custos e benefícios.

A vida útil dos pneus depende de vários fatores externos e internos da empresa segundo FABET (2010) e ANIP (2014), como a conservação dos veículos, da forma 
como os motoristas conduzem os veículos, do trânsito, do clima, do relevo, das estradas, do peso das cargas transportadas, dos tipos de veículos utilizados e da manutenção.

As funções que o pneu deve apresentar como um recipiente de pressão, e o único ponto de apoio do veículo a superfície da estrada, são: (a) capacidade de suportar e transportar cargas, (b) capacidade amortecedora, (c) capacidade de transmissão de torque, (d) capacidade de resposta direcional e (d) capacidade de aderência ao solo (ANIP, 2014; GOODYEAR, 2010; DARIO, 2012; BBTS, 2010 e FABET, 2010).

O pneu também deve oferecer uma durabilidade satisfatória, e proporcionar segurança para o desempenho dos veículos, além da satisfação dos profissionais de transporte, como: a) baixa resistência ao rolamento e economia de combustível, baixo nível de ruído, possibilidade de ressulcagem e consertos, possibilidade de recauchutagens e capacidade de velocidade alta dentro dos padrões técnicos e legais (GOODYEAR, 2010). Os fatores que reduzem a vida útil dos pneus de forma inadequada conforme a Bridgestone Bandag Tire Solutions - BBTS (2010), são os cinco ladrões de quilometragem: (a) alinhamento; (b) balanceamento; (c) controle de pressão; (d) desenho de banda de rodagem; (e) emparelhamento.

O alinhamento do eixo dianteiro é uma condição existente pela legislação de transito, segundo o Conselho Nacional de Transito - CONTRAN (558/80), sob pena de multa e apreensão do veículo (sendo o uso exclusivo de pneu novo, mínimo de sulco de retirado do pneu em $1,6 \mathrm{~mm}$ do menor ponto do pneu) (ANIP, 2014). O desalinhamento do eixo dianteiro é o que mais afeta a vida dos pneus em serviço das empresas, uma vez que provoca o arraste dos pneus causando desgastes irregulares, nas empresas que não fazem alinhamento e balanceamento, ou fazem no máximo, uma vez em cada troca dos pneus (DARIO, 2012).

Os balanceamentos reduzem as quilometragens e podem ser de três tipos: (a) desequilíbrio estático; (b) desequilíbrio dinâmico; e (c) ambos; estáticos e dinâmicos juntos. Os desbalanceamentos, além de ser desconfortável ao volante, causa um desgaste irregular e prematuro dos pneus, dos rolamentos do cubo e dos amortecedores. 
O controle de pressão de forma inadequada reduz a quilometragem dos pneus na ordem de $30 \%$, conduzindo a uma perda média de $50 \%$ na sua vida útil. Já com excesso de $30 \%$ de peso, perde-se $15 \%$ da vida útil (BRIDGESTONE BANDAG TIRE SOLUTIONS - BBTS, 2010). A pior condição é a falta de pressão, que acelera o desgaste e aumenta o consumo de combustível, além de reduzir a recapabilidade, por isso é um dos fatores mais importantes para a boa manutenção preventiva do pneu (GOODYEAR, 2010).

GOODYEAR (2010) e BBTS, (2010) apontam que os diferentes tipos de pressão por inflação são: (a) na baixa pressão o pneu se flexionará e não terá um assentamento correto sobre o solo, desgastando-se mais nos ombros e perdendo 0 contato necessário para tração e aderência adequada, (b) o uso da calibração adequada, conforme recomendação dos fabricantes e a realização da calibragem a cada 15 dias condiz a correto contato do pneu sobre o solo; (c) alta pressão ou excesso de pressão causa um arqueamento irregular do pneu, resultando em perda de contato e aderência. Também desgasta mais o centro do pneu, deixando-o sofrer mais com o risco de impactos, pois a capacidade de assimilação diminui à medida que o pneu fica mais duro.

Outro fator de redução de custo é o emparelhamento incorreto ou inadequado dos pneus, os pneus desemparelhados resultam na distribuição desigual da carga, devido à variação de diâmetro dos pneus, pois rodam com a mesma velocidade, como resultado será um desgaste rápido e irregular do desenho e sobrecarga num dos pneus, pois fatores como: diferença de pressão, os abaulamentos das estradas impedem o correto emparelhamento das rodas duplas (GOODYEAR, 2010; BBTS, 2010 e ANIP, 2014).

Por outro lado, os sistemas de medição de desempenho têm despertado o interesse de diversos estudos (NARAYAN, 2012; PERES e LIMA, 2008; AMBRÓSIO e LEITE, 2008). Um sistema de medição de desempenho pode ser definido com um conjunto de medidas utilizadas para quantificar eficiência e eficácia das ações $A$ medição de desempenho é o processo de quantificar uma ação e está fortemente ligado à eficiência e efetividade (NEELY et al., 2005). Um sistema de medição de desempenho pode ser analisado em três diferentes níveis: $1^{\circ}$ ) individuais; $2^{\circ}$ ) conjunto 
de medidas de desempenho; e $3^{\circ}$ ) relação entre o sistema de medição desempenho e o ambiente onde está inserido.

Vale ressaltar que as organizações comumente adotam Sistemas de Medição de Desempenho (SMD) para avaliar de forma mais ampla seu desempenho, em diversas áreas de seu negócio, como por exemplo; a) o Balanced Scorecard - BSC (KAPLAN e NORTON, 1992); b) Sete Critérios de Desempenho (SINK e TUTTLE, 1985); c) Desempenho Quantum (HRONEC, 1994); d) Sistema de Medição de Desempenho por Gestão de Processos (DE TONI e TONCHIA, 2001); d) SMART - Performance Pyramid (CROSS e LYNCH, 1990); e) Sistema de Medição de Desempenho Integrado de (BITITCI e TURNER, 1997); f) Sistema de Medição de Desempenho de Integrado e Dinâmico (GHALAYINI et al., 1997); g) Modelo Performance Prism (ESPOSTO, 2008).

Valente et al. (2003) e Mattar et al. (2010) citam que os principais indicadores e variáveis para medir o desempenho de uma gestão de frota, são: velocidade operacional, tempo de carga e descarga, horas de trabalho, redução de custo, incluindo indicadores voltados para a manutenção, pneus e combustíveis. Portanto, sendo esses indicadores são considerados de consumo e operacionais da frota.

Já Francischini (1998), afirma que numa visão abrangente, produtividade pode ser definida como uma relação entre um resultado e um esforço. Slack et al (1996) enfatizam que a função produção bem sucedida, para dar uma vantagem baseada na produção, é possível através de cinco objetivos de desempenho: vantagem em qualidade, rapidez, confiabilidade, flexibilidade e custo. Nordskag (2006), define o "Overall Equipment Effectiveness" (OEE) ou índice de eficiência global, baseado em três elementos básicos: disponibilidade, capacidade, qualidade. Os indicadores, deste estudo tem por finalidade identificar as principais ameaças à operação.

Em síntese, considerando as operações dos processos internos associados a manutenção, a pesquisa, na literatura mencionada nesta seção, revelou que seus indicadores de resultados estejam associados aos custo total da manutenção, como: calibragens dos pneus, alinhamentos dos veículos, balanceamento, ordens de serviço, socorros nas estradas, índice de sucateamento de pneu, horas de treinamento, indicadores de segurança e saúde do trabalho, consumo de combustível, reclamação 
de clientes, acidentes, custo aplicado aos pneus, gasto com pneus na estrada e custo do pneu por km rodado. Tais indicadores serão adotados como categorias de análises para a investigação dos dados empíricos do presente estudo. Portanto, esses estudos ajudaram a compor um conjunto de categorias de análise desenvolvidos na síntese desta revisão teórica, uma vez que não foram encontradas medidas desempenho específicas da manutenção na gestão de pneus, sendo esta uma das questões de pesquisa do presente trabalho.

\section{METODO, AMOSTRA E COLETA DE DADOS}

A presente pesquisa é caracterizada como um estudo de caso exploratório, descritivo e explanatório (YIN, 2010). Exploratório porque foi aplicado em áreas nas quais há poucas teorias ou um conjunto deficiente de conhecimentos, sendo as principais teorias, gestão da manutenção na gestão de pneus e desempenho em ambas as áreas de uma empresa de transportes rodoviários de cargas. Foi considerado descritivo porque se procurou descrever as práticas de manutenção na gestão de pneus, bem como identificar os indicadores de desempenho na gestão de pneus da empresa pesquisada e explanatório (explicativo) busca da relação causal.

Os principais instrumentos de coleta de dados foram à observação direta in loco, entrevista não estruturada e análise de documentos e de relatórios sobre resultados dos indicadores. A coleta desses dados ocorreu nos meses de setembro a dezembro de 2011, sendo que os dados coletados se referem a levantamento histórico das práticas implantadas desde o ano de 2003 e indicadores de desempenho operacionais apurados dos relatórios entre os anos de 2009 a 2011.

As principais variáveis encontradas foram: valor de alinhamentos, valor de balanceamentos, quilometragem da frota rodado, custo aplicado aos pneus, número de ordens de serviço, custo da manutenção, número de pneus sucateados, números de veículos calibrados, custo da quilometragem do pneu, gasto com pneus nas estradas, custo de mão de obra na manutenção. 
A análise dos dados foi realizada em duas fases: (a) análise qualitativa: em que foi utilizada a análise de conteúdo (COLLIS e HUSSEY, 2005), mediante uma apresentação descritiva da implantação das práticas e dos indicadores de desempenho da gestão de manutenção e pneus; (b) análise quantitativa: em que foi empregada a análise de correlação Pearson buscando analisar as associações entre medidas da manutenção e de pneus. Foi também empregado à análise de regressão múltipla (HAIR JÚNIOR et al., 2005), para analisar os quanto o custo de pneus representam (explicam) sobre os custos de manutenção.

\section{RESULTADOS DA PESQUISA}

A empresa em estudo é do setor de transportes rodoviários de cargas e foi fundada em outubro de 1971 na cidade de Piracicaba/SP. Atualmente a área da matriz, composta por administração, mecânica, manutenção e abastecimento, possui 30.000 m2. Também, possui uma área de pátio externo nomeado de garagem dos veículos, com $50.000 \mathrm{~m} 2$.

Existem seis filiais, que estão nas cidades de Araucária/PR, Serra/ES, São Paulo/SP, Jacareí/SP, Mogi das Cruzes/SP e Santos-SP. Tem 550 funcionários entre a matriz e filiais. Sua frota é composta de 32 caminhões trucks, 150 cavalos mecânicos, com 156 semi-reboques cargas secas, 50 pranchas, 7 semi-reboques porta containeres, 16 semi-reboques siders, 80 semi-reboques tanques de GLP, 07 veículos camionetes, totalizando 498 veículos com idade média de 05 anos.

Percorre em média $1.650 .000 \mathrm{~km}$ mensais, sendo $1.300 .000 \mathrm{~km}$ com frota própria e $350.000 \mathrm{~km}$ com veículos terceirizados. Transporta aproximadamente 35.000 toneladas mensais. A área de segmento de transporte da empresa em estudo é o transporte de GLP, máquinas e equipamentos, papel e celulose e cargas industriais e fracionadas.

A administração é de caráter familiar. Os principais parentescos são os filhos e netos do fundador na direção da empresa. É certificada pela ISO 9001/2008, pela Sassmaq desde 2004 e em 2006 foi a primeiro transportador a aderir ao programa Siga 
Bem Criança, firmando uma parceria, patrocinado com a Petrobrás. No ano de 2009, 2010 e 2011 a empresa foi o transportador oficial da Formula 1 e da Fórmula Indy Americana.

A manutenção da empresa em estudo começou a se organizar a partir de 2003. Antes desse ano, a manutenção era baseada somente em corretivas e trocas de óleo, não tinha um gerenciamento de pneus, dependia de unicamente de um controlador de pneus. Não tinha controle em seus processos, sendo a manutenção corretiva anotada em cadernos e fichas, o mesmo acontecendo com os pneus. Dessa forma, classificada como manutenção não planejada.

No final de 2003 e início de 2004 houve a implantação da ISO 9001, uma vez que a empresa objetivava a se adaptar as novas normas de manutenção mundial. Então, a manutenção buscou o conceito de ser planejada, com foco na manutenção preventiva e corretiva, realizando o chek-list de inspeção, e tentando implantar a medida de seu crescimento a manutenção detectiva e a engenharia de manutenção. Portanto, novas ferramentas ou programas de ação foram implantados paulatinamente, tendo vista fatores como custo de implantação das práticas de manutenção, os resultados alcançados e tempo de implantação. Em 2003 a empresa possuía apenas 15 funcionários responsáveis pela manutenção dos veículos. As ferramentas ou programa de ações, seus referidos anos de implantação e seus propósitos foram:

- 2003 a 2004 - a implantação da ISO e implantação de softwares de gerenciamento da manutenção.

- 2005 A 2006 - Manutenção estava no check-list com mais de 80 itens de inspeção.

- 2006 - Pneus: dizia respeito ao controle e monitoramento dos pneus, registro das movimentações, calibragem e sucateamento dos pneus, estava no check-list.

- 2007 a 2008. A empresa continuou com as mesmas ferramentas implantadas, visando à revalidação da ISO 9001. Nesse período, os números de veículos aumentaram e seus indicadores e desempenho sofreram interferência em níveis aceitáveis, como a queda de controle de 
seus processos na área operacional. Adicionalmente a empresa precisou adquirir mais 02 áreas externas da matriz para pátio de estacionamento dos veículos, onde dificultou ainda mais seus controles internos referentes à manutenção e pneus.

- 2009 a 2011. Foi o período que mais afetou a manutenção e a gestão de pneus, tendo em vista a falta de motoristas qualificados no mercado aumentando assim os custos operacionais de manutenção e pneus.

Em se tratando dos indicadores de desempenho, estes estavam associados aos resultados da organização, com base no fornecimento de informações que ajudam a apontar ações sobre a gestão dos processos dos negócios da empresa, vinculados aos requisitos dos clientes e aos requisitos da organização e, também, à documentação interna sobre os objetivos e política da qualidade. Os principais indicadores adotados e seus referidos conceitos voltados para a gestão da manutenção na gestão de pneu eram: custo da manutenção; índice de sucateamento de pneus; horas de treinamento; indicador de segurança e saúde do trabalho; consumo de combustível e indicador de reclamação de cliente.

Os indicadores de custo da manutenção, índice de sucateamento, horas de treinamento, consumo de combustível, indicador de reclamação de clientes foram implantados primeiramente conjuntamente na implantação da ISO 9001/2008, para trabalharem com empresas multinacionais do ramo maquinas e equipamentos. Quanto aos transportes de Gás Liquefeito de Petróleo (GLP), a empresa na mesma época da implantação da ISO, para o transporte de produtos químicos, precisou implantar a Sassmaq, empresas como a Liquigás (Grupo Petrobrás), Ultragáz, filiadas a Associação Brasileira de Indústrias Químicas (ABIQUIM) exigiam tal certificação, e os indicadores de segurança, saúde do trabalho e meio ambiente foram também implantados.

Já o sistema de gestão integrado, envolvendo a ISO 9001 e Sassmaq, possuía um conjunto de sete indicadores, voltados para a segurança e saúde do trabalho: Taxa de freqüência de acidentes típicos com afastamento, Taxa de gravidade de acidentes típicos, Número de óbitos em função de acidente de trabalho, Número de acidentes 
incapacitantes, Números de acidentes sem vazamentos, Números de acidentes com vazamento e Números de acidente com morte, ferimentos sérios ou relevante impacto ambiental.

Era realizada uma reunião de indicadores de desempenho por mês, envolvendo as áreas operacionais, para expor os resultados junto aos diretores da empresa.

Também, era realizada uma reunião de análise critica pela direção a cada três meses com o propósito de avaliar os resultados dos indicadores e se a política de qualidade estava adequada com o plano de negócio da empresa, além de avaliar os resultados da auditoria (interna e externa) e o atendimento ao cliente.

Foi verificado na revisão teórica que as principais práticas de manutenção em empresas de transportes rodoviários voltadas para o monitoramento dos pneus são; a TPM, 5S's e multiespecialização. Já a pesquisa prática revelou que a empresa pesquisada possui alguns pilares da TPM; como melhoria da qualidade da norma da ISO 9001, PDCA, manutenção autônoma, 5S's, Controle e Segurança, Higiene e Meio Ambiente (Sassmaq). Ainda a empresa não possui a implantação da TPM por completo, por ainda faltar à manutenção planejada, treinamento e capacitação dos colaboradores envolvidos, além da não eficiência no controle de confiabilidade de suas filiais.

Também foi revelado que a gestão da manutenção foi impulsionada e apoiada pela implantação da gestão da qualidade total, que envolveu a adoção de uma séria de práticas: 5S's, PDCA, Análise de Pareto e Diagrama de Ishikawa, sendo que a adoção de tais ferramentas foi voltada para a manutenção e na gestão de pneus.

Em se tratando dos indicadores de desempenho, foi constato que na revisão teórica pouco se tem pesquisado a respeito de indicadores voltados para a manutenção e gestão de pneus. Assim, os indicadores coletados e seus conceitos contribuem para aumentar o conhecimento a respeito da medição de desempenho nessa área. Assim, os indicadores coletados e seus conceitos contribuem para aumentar o conhecimento a respeito da medição de desempenho nessa área.

O Quadro 1 apresenta uma síntese da revisão teórica e dos dados coletados na pesquisa de campo sobre as práticas e indicadores de desempenho da manutenção na 
gestão de pneus. Os dados Quadro 1 respondem as questões um e dois (Q1 e Q2) de pesquisa, que são: (Q1) Quais são as práticas da gestão da manutenção que representam o conceito de manutenção na gestão de pneus? (Q2) - Quais são os indicadores de desempenho operacionais da manutenção na gestão de pneus?

Quadro 1 - Práticas e indicadores de desempenho da manutenção na gestão de pneus

\begin{tabular}{|c|c|}
\hline Encontradas na revisão teórica & Identificadas na pesquisa empírica \\
\hline $\begin{array}{l}\text { TPM. (KARDECH e NASCIF, 2001; } \\
\text { LIMA, 2008; ABRAMAN, 2011). } \\
\text { 5S's. (KARDECH e NASCIF, 2001; } \\
\text { LIMA, 2008; ABRAMAN, 2011) } \\
\text { Multiespecialização. (KARDECH e } \\
\text { NASCIF, 2001; LIMA, 2008; } \\
\text { ABRAMAN, 2011). } \\
\text { Cinco ladrões de quilometragem. } \\
\text { (Alinhamento, balanceamento, } \\
\text { controle de pressão, desenho de } \\
\text { banda de rodagem e } \\
\text { emparelhamento) (Goodyear, 2010; } \\
\text { RevistaScania). } \\
\text { Check- list. (BBTS, 2010) }\end{array}$ & $\begin{array}{l}\text { Programa de Qualidade Total. (PQT) (Pesquisa } \\
\text { empírica) } \\
\text { PDCA. (Pesquisa empírica) } \\
\text { Manutenções corretivas. (Pesquisa empírica) } \\
\text { Manutenções preventivas (Pesquisa empírica) } \\
\text { Análise de Pareto. (Pesquisa empírica) } \\
\text { Diagrama de Ishikawa. (Pesquisa empírica) } \\
8 S^{\prime} \text { 's } \\
\text { Cinco ladrões de quilometragem }\end{array}$ \\
\hline \multicolumn{2}{|c|}{ Indicadores de desempenho identificados na pesquisa empírica } \\
\hline $\begin{array}{l}\text { Custo total da manutenção } \\
\text { Calibragem de pneus } \\
\text { Alinhamento de veículos } \\
\text { Balanceamento das rodas de pneus } \\
\text { Ordens de serviço de manutenção } \\
\text { Socorros na estrada devido à } \\
\text { manutenção de pneus } \\
\text { Índice de sucateamento } \\
\text { Horas de treinamento } \\
\text { Indicador de segurança e saúde do } \\
\text { trabalho de combustível } \\
\text { Consumo de } \\
\text { Indicador de reclamação de clientes }\end{array}$ & $\begin{array}{l}\text { Taxa de frequência de acidentes típicos com } \\
\text { afastamento } \\
\text { Taxa de gravidade de acidentes típicos } \\
\text { Número de óbitos em função de acidente de } \\
\text { trabalho } \\
\text { Número de acidentes incapacitantes } \\
\text { Números de acidentes sem vazamentos } \\
\text { Números de acidentes com vazamento } \\
\text { Números de acidente com morte, ferimento sério } \\
\text { ou relevante impacto ambiental } \\
\text { Custo aplicado dos pneus } \\
\text { Custo do pneu por Km rodado (CPK) } \\
\text { Gastos com pneus na estrada }\end{array}$ \\
\hline
\end{tabular}

Fonte: Elaborado pelos autores

A empresa pesquisada disponibilizou o acesso de alguns resultados de valores absolutos dos indicadores de desempenho da área de manutenção na gestão de pneus identificados, conforme Quadro 1. Tais resultados dizem respeito a dados de 33 meses, que se referem aos meses de janeiro de 2009 a setembro de 2011. A próxima seção apresenta as análises quantitativas desses dados. 


\subsection{Análises dos Dados}

Segundo Yin (2010), "A análise de dados consiste em examinar, categorizar, classificar em tabelas, testar ou, do contrário, recombinar as evidências quantitativas e qualitativas para tratar as proposições iniciais de um estudo".

Mediante as observações diretas no setor de manutenção na gestão de pneus e os indicadores coletados, conforme relatados anteriormente, foi formulada a seguinte hipótese de pesquisa: H1: Quanto maior os custos aplicados aos pneus, maior será o custo total da manutenção. O teste desta hipótese, responde as questões (Q3 e Q4), formuladas na introdução deste trabalho, que são: (Q3) - quais medidas da área de manutenção na gestão de pneus estão associadas significativamente aos desempenhos de custos pneus? (Q4) Os custos aplicados aos pneus influenciam significativamente o custo total de manutenção?

Foi usado o Software Estatístico Statistical Packge for Social Sciences (SPSS), versão 10, para o emprego das técnicas de correlação de Pearson e análise de regressão nas variáveis de manutenção e pneus. A Tabela 1 apresenta os resultados da análise de correlação de Pearson entre os indicadores de desempenho da área de manutenção na gestão de pneus. Das 55 correlações entre as variáveis de indicadores de desempenho da manutenção na gestão pneus, foram encontradas 23 correlações não significativas $(p>0,05)$ (assinaladas em negrito, Tabela 1), 31 correlações significativas $(p \leq 0,05)$ e 01 correlação negativa, estatisticamente significativa $(p=$ 0,05 ) (em itálico). Dentre as correlações não significativas foram observadas 04 correlações negativas, que se referem a variável CPK versus valor alinhamento, valor balanceamento, números de ordens de serviços, custo da manutenção e números de pneus sucateados. Nota-se que houve 01 correlação negativa e significativa entre CPK e o número de ordens de serviço ( $r=-0,35$ e $p=0,05)$ (Tabela 2$)$. 
Tabela 2 - Correlação entre os indicadores de desempenho da área de Manutenção na gestão pneus

\begin{tabular}{|c|c|c|c|c|c|c|c|c|c|c|c|c|}
\hline Variáveis & & $\begin{array}{l}\geqq \\
\frac{z}{\varangle} \\
\stackrel{\nwarrow}{>}\end{array}$ & 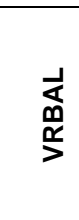 & $\begin{array}{l}\text { 呆 } \\
\text { o } \\
\sum \\
\sum\end{array}$ & 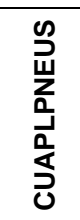 & 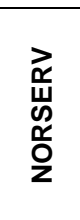 & $\begin{array}{l}z \\
\vdots \\
0 \\
0 \\
0 \\
0\end{array}$ & 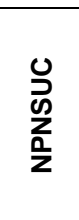 & 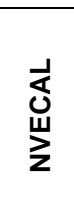 & $\frac{y}{0}$ & 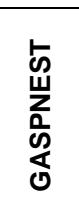 & 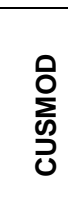 \\
\hline VRALIN & $\begin{array}{l}r \\
\text { Sig. }\end{array}$ & 1,00 & & & & & & & & & & \\
\hline VRBAL & Sig. & $\begin{array}{l}0,41 \\
0,02\end{array}$ & 1,00 & & & & & & & & & \\
\hline KMTOFR & $\begin{array}{l}r \\
\text { Sig. }\end{array}$ & $\begin{array}{l}0,62 \\
0,00\end{array}$ & $\begin{array}{l}0,60 \\
0,00\end{array}$ & 1,00 & & & & & & & & \\
\hline CUAPLPNEUS & $\begin{array}{l}r \\
\text { Sig. }\end{array}$ & $\begin{array}{l}0,26 \\
0,15\end{array}$ & $\begin{array}{l}0,30 \\
0,09\end{array}$ & $\begin{array}{l}0,32 \\
0,07\end{array}$ & 1,0 & & & & & & & \\
\hline NORSERV & $\begin{array}{l}r \\
\text { Sig. }\end{array}$ & $\begin{array}{l}0,32 \\
0,07\end{array}$ & $\begin{array}{l}0,65 \\
0,00\end{array}$ & $\begin{array}{l}0,63 \\
0,00\end{array}$ & $\begin{array}{l}0,47 \\
0,01\end{array}$ & 1,00 & & & & & & \\
\hline CUSTOMAN & Sig. & $\begin{array}{l}0,43 \\
0,01\end{array}$ & $\begin{array}{l}0,36 \\
0,04\end{array}$ & $\begin{array}{l}0,38 \\
0,03\end{array}$ & $\begin{array}{l}0,73 \\
0,00\end{array}$ & $\begin{array}{l}0,56 \\
0,00\end{array}$ & 1,00 & & & & & \\
\hline NPNSUC & Sig. & $\begin{array}{l}0,43 \\
0,01\end{array}$ & $\begin{array}{l}0,21 \\
0,25\end{array}$ & $\begin{array}{l}0,55 \\
0,00\end{array}$ & $\begin{array}{l}0,44 \\
0,01\end{array}$ & $\begin{array}{l}0,41 \\
0,02\end{array}$ & $\begin{array}{l}0,43 \\
0,01\end{array}$ & 1,00 & & & & \\
\hline NVECAL & $\begin{array}{l}r \\
\text { Sig. }\end{array}$ & $\begin{array}{c}0,68 \\
0,00 \\
-0,04\end{array}$ & $\begin{array}{l}0,43 \\
0,01 \\
-0,16\end{array}$ & $\begin{array}{l}0,78 \\
0,00 \\
\mathbf{0 , 0 4}\end{array}$ & $\begin{array}{l}0,44 \\
0,01 \\
\mathbf{0 , 0 5}\end{array}$ & $\begin{array}{l}0,44 \\
0,01 \\
-\end{array}$ & $\begin{array}{l}0,55 \\
0,00 \\
-\end{array}$ & $\begin{array}{l}0,70 \\
0,00 \\
-\end{array}$ & $\begin{array}{l}1,00 \\
\text { - }\end{array}$ & 1,00 & & \\
\hline CPK & Sig. & 0,85 & 0,38 & 0,83 & 0,78 & $\begin{array}{l}0,35 \\
0,05\end{array}$ & $\begin{array}{l}0,35 \\
0,05\end{array}$ & $\begin{array}{l}0,05 \\
0,79\end{array}$ & $\begin{array}{l}0,08 \\
0,67\end{array}$ & & & \\
\hline GASPNEST & $\begin{array}{l}r \\
\text { Sig. }\end{array}$ & $\begin{array}{l}0,30 \\
0,09\end{array}$ & $\begin{array}{l}0,10 \\
0,58\end{array}$ & $\begin{array}{l}0,51 \\
0,00\end{array}$ & $\begin{array}{l}0,32 \\
0,07\end{array}$ & $\begin{array}{l}0,33 \\
0,06\end{array}$ & $\begin{array}{l}0,11 \\
0,54\end{array}$ & $\begin{array}{l}0.49 \\
0.00\end{array}$ & $\begin{array}{l}0,42 \\
0,01\end{array}$ & $\begin{array}{l}0,24 \\
0,18\end{array}$ & 1,00 & \\
\hline CUSMOD & $\begin{array}{l}r \\
\text { Sig. }\end{array}$ & $\begin{array}{l}0,36 \\
0,04\end{array}$ & $\begin{array}{l}0,50 \\
0,00\end{array}$ & $\begin{array}{l}0,63 \\
0,00\end{array}$ & $\begin{array}{l}0,02 \\
0,90\end{array}$ & $\begin{array}{l}0,53 \\
0,00\end{array}$ & $\begin{array}{l}0,26 \\
0,14\end{array}$ & $\begin{array}{l}0,26 \\
0,15\end{array}$ & $\begin{array}{l}0,52 \\
0,00\end{array}$ & $\begin{array}{l}0,01 \\
0,97\end{array}$ & $\begin{array}{l}0,17 \\
0,34\end{array}$ & 1,00 \\
\hline
\end{tabular}

Legenda: VRALIN (valor do alinhamento), VRBAL (valor do balanceamento), KMTOFR (kilometragem total da frota), CUAPLPNEUS (custos aplicados com pneus), NORSERV (número de ordens de serviços), CUSTOMAN (custo total de manutenção), NPNSUC (número de pneus sucateados), NVECAL (número de veículos calibrados), CPK (custos de pneus por kilometragem), GASPNEST (gastos com pneus nas estradas) e CUSMOD (custo de mão de obra de serviço).

Já as duas correlações mais fortes e altamente significativas verificadas foram:

- Números de veículos calibrados versus quilometragem da frota $(r=0,78$ e $p=0,00)$. Isto indica que quanto maior for o número de veículos calibrados, maior será o número da quilometragem da frota. Na prática uma pressão correta significa a relação da pressão verificada com a porcentagem de vida útil do pneu (durabilidade). Por exemplo, 6.000 pneus de uma frota rodam $1.425 .000 \mathrm{~km}$ por mês. Se todos os pneus da frota estiverem $100 \%$ calibrados, então se concluí que todos os pneus têm durabilidade de $100 \%$. Se a pressão dos pneus for de $80 \%$, a durabilidade do pneu será de $78 \%$. Se a calibragem da frota for $70 \%$ a durabilidade dos pneus será de $67 \%$ e assim por diante. Portanto, quanto maior for à quilometragem percorrida, maior será a necessidade de 
calibragens de pneus da frota e conseqüentemente, menor é custo por quilometro rodado (CPK).

- Custos de pneus aplicados versus custo da manutenção $(r=0,73$ e $p=0,03)$. Quanto maior os custos aplicados aos pneus, maior é o custo da manutenção. $\mathrm{Na}$ prática ao analisar os dados brutos, percebe-se que quando os gastos com pneus aumentam, os mesmos ocorreram com o custo de manutenção e vice-versa. Isto demonstra a importância dos gastos dos pneus aplicados na manutenção, onde é preciso fazer uma análise destes para saber o quanto estes custos representam no custo total da manutenção. Tal análise é feita a seguir pela técnica de análise de regressão.

Foi desenvolvida a análise regressão simples e múltipla, que teve o objetivo de analisar a influência de variáveis independentes sobre a variável dependente "custo total da manutenção". No primeiro momento foi empregado um modelo de regressão simples, onde foi relacionada à variável que apresentou maior correlação com a variável dependente "custo total da manutenção". Essa variável foi "custos aplicados aos pneus" cuja correlação foi 0,734 e significância 0,00 (Tabela 2).

$\mathrm{Na}$ sequência, foram acrescidas outras variáveis independentes ao modelo de regressão para verificar quais outras variáveis também influenciavam na variação do custo total da manutenção (variável independente). Assim, foram feitos testes de correlações parciais, isolando os efeitos de variáveis de controle já incluídas nos modelos de regressão a fim de verificar qual variável apresentava um maior coeficiente de correlação e significativo com o custo total da manutenção. $\mathrm{Na}$ Tabela 3, são apresentados os resultados das análises de regressão simples e múltipla, nomeados de modelos a, b e c. Observa-se que a variável dependente é o "custo total da manutenção" e as variáveis independentes estão listas na nota da Tabela 3, conforme o modelo avaliado. 
Tabela 3 - Resumo dos modelos de regressão a, b e c

\begin{tabular}{cccll}
\hline Modelos & $\mathbf{R}$ & $\mathbf{R 2}$ & $\mathbf{R 2}$ ajustado & Erro padrão estimado \\
\hline a & $0,73 \mathrm{a}$ & 0,54 & 0,52 & $64.788,30$ \\
b & $0,77 \mathrm{~b}$ & 0,60 & 0,58 & $61.166,72$ \\
c & $0,80 \mathrm{c}$ & 0,65 & 0,62 & $57.996,77$ \\
\hline
\end{tabular}

Nota: (a) Indicadores: (Constante), custos aplicados aos pneus, (b) Indicadores: (Constante), custos aplicados aos pneus, número de veículos calibrados, (c) Indicadores: (Constante), custos aplicados aos pneus, número de veículos calibrados e custos com pneus nas estradas.

O R reflete o grau de associação entre a variável dependente (custo total da manutenção) e a variável independente (custos aplicados aos pneus), que é 0,73 (Tabela 2, modelo a). O R2 é o coeficiente de determinação, indica que $54 \%$ da variação na variável dependente (custo total da manutenção) é explicada pelas variações ocorridas na variável independente (custos aplicados aos pneus) (Tabela 3 , modelo a).

Outra medida importante na avaliação da precisão dos modelos de regressão é o erro padrão estimado. Ao observar os modelos de regressão múltipla a, b e c (Tabela 3) o erro padrão diminuiu. Assim, quanto menor o erro padrão, melhor o modelo estimado (CUNHA e COELHO, 2009).

O teste ANOVA (Tabela 4) fornece os resultados da soma dos quadrados dos resíduos. Quanto menor for este resultado, melhor o modelo estimado, pois este indica a parte não explicada pelas variáveis independes sobre a variável dependente. Observa-se a soma dos quadrados dos resíduos (valor residual) diminuiu entre os modelos a, b e c (Tabela 4). Também verifica a influência significativa das variáveis independentes sobre a variável dependente, indicando significância estatística nos três modelos (Tabela 4).

Tabela 4 - Teste Anova para os modelos de regressão a, b e c

\begin{tabular}{|c|c|c|c|c|c|}
\hline Modelos & $\begin{array}{c}\text { Soma dos } \\
\text { quadrados }\end{array}$ & df & Média & $F$ & Sig. \\
\hline Regressão a & $152.333 .720 .081,75$ & 1 & $152.333 .720 .081,75$ & 36,29 & $0,000^{\mathrm{a}}$ \\
\hline Residual & $130.123 .221 .638,46$ & 31 & $41.975 .223 .278,66$ & & \\
\hline Total & 282.456.941.720,22 & 32 & & & \\
\hline Regressão b & $170.215 .911 .487,89$ & 2 & $85.107 .955 .743,94$ & 22,75 & $0,000 b$ \\
\hline $\begin{array}{l}\text { Residual } \\
\text { Total }\end{array}$ & $112.241 .030 .232,33$ & 30 & & & \\
\hline Regressão c & $184.911 .796 .888,29$ & 3 & $1.637 .265 .629,43$ & 18,32 & $0,000 c$ \\
\hline Residual & $97.545 .144 .831,93$ & 29 & 3.363.625.683,86 & & \\
\hline Total & 282.456.941.720,22 & 32 & & & \\
\hline
\end{tabular}

Revista Produção Online, Florianópolis, SC, v.14, n. 4, p.1235-1269, out./dez. 2014. 
Nota: (a) Indicadores: (Constante), custos aplicados aos pneus.

(b) Indicadores: (Constante), custos aplicados aos pneus, número de veículos calibrados.

(c) Indicadores: (Constante), custos aplicados aos pneus, número de veículos calibrados e custos com pneus nas estradas.

Em se tratando da hipótese $(\mathrm{H} 1)$ de que quanto maiores forem os custos aplicados aos pneus, maiores serão os custos da manutenção, esta é confirmada pela análise de regressão simples e múltipla, onde os coeficientes padronizados betas, dos custos aplicados aos pneus, apresentaram em maior magnitude nos três modelos (a, b e c, Tabela 5). Ademais, os indicadores avaliados no modelo c são indicadores relacionados a pneus em que foi constado que esses influenciam em $65 \%$ da variação do custo total da manutenção. Além disso, o indicador de "gastos com pneus nas estradas" teve um coeficiente negativo $(-0,26)$ (Tabela 5 modelo $c$ ), decorrendo que quanto maiores forem os gastos com pneus nas estradas, menores serão os custos de manutenção.

Tabela 5 - Coeficientes para os modelos de regressão a, b e c

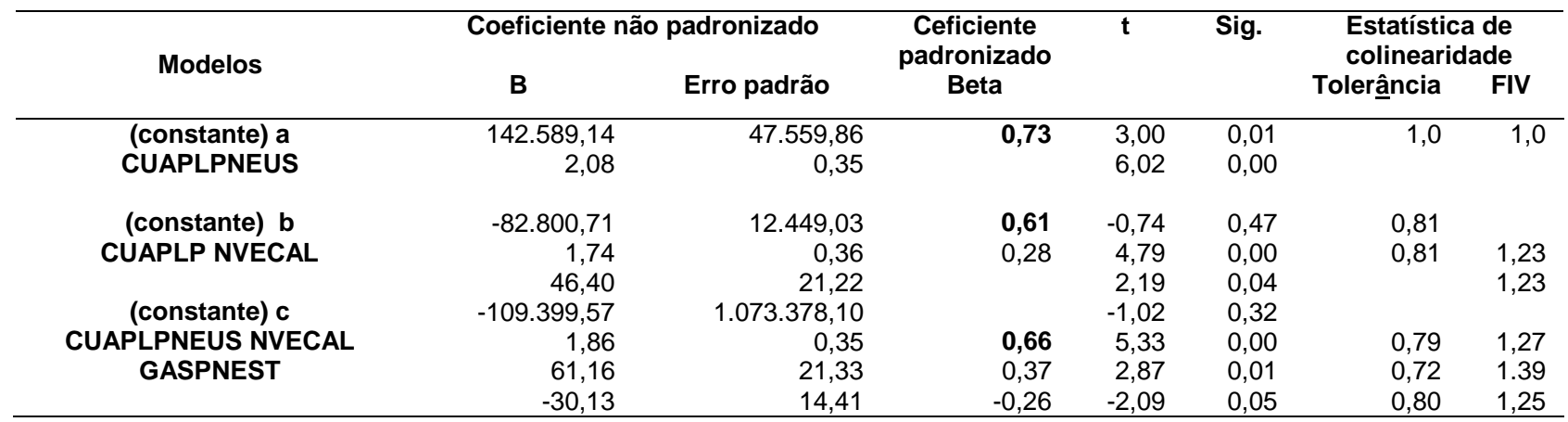

Nota: (a) Indicadores: (Constante), custos aplicados aos pneus; (b) Indicadores: (Constante), custos aplicados aos pneus, número de veículos calibrados; (c) Indicadores: (Constante), custos aplicados aos pneus (CUAPLPNEUS), número de veículos calibrados (NVECAL) e custos com pneus nas estradas (GASPNEST).

Os valores gastos com pneus das estradas dizem respeito somente à troca ou substituição do pneu. O custo desta substituição é feito através de um chek-list, que é efetuado na manutenção através de número de ordens de serviço, aumentando-se os custos totais com manutenção. No entanto, ao observar a correlação de Pearson (Tabela 3) percebe-se que os gastos com pneus nas estradas não foram significativos no número de ordens de produção ( $r=0,33$ e sig. 0,06$)$. Assim, o resultado negativo do 
coeficiente beta da análise de regressão múltipla entre gastos com pneus nas estradas e custo total de manutenção pode ser em decorrência da não significância entre o primeiro sobre as ordens de serviço de manutenção.

Por fim, os testes da multicolinearidade (multicolinearidade refere-se à correlação entre três ou mais variáveis independentes (Tabela 5). O que precisa ser feito é procurar variáveis independentes que tenham baixa multicolinearidade com as outras variáveis independentes, mas também apresentem correlações elevadas com a variável dependente. Segundo Hair Junior et al. (2005), além dos efeitos na explicação, a multicolinearidade pode ter sérios efeitos nas estimativas dos coeficientes de regressão e na aplicabilidade geral do modelo "estimado" entre as variáveis independentes indicaram não haver multicolinearidade entre as variáveis independentes.

Segundo Hair Junior et al. (2005), o valor máximo aceitável de VIF seria 5,0, qualquer valor acima deste indicaria problemas de multicolinearidade. Enquanto que valores de tolerância abaixo de 0,10 indicariam problema com multicolinearidade.

Vale dizer que outros modelos foram gerados a fim de verificar a influência de demais variáveis sobre o custo total da manutenção. Foram testados modelos avaliando as correlações parciais entre as variáveis, sendo controladas as variáveis independentes já inseridas nos modelos anteriores. Entretanto, os resultados do coeficiente beta não foram significativos indicando que as demais variáveis deveriam ser retiradas do modelo.

\subsection{Discussões}

Do ponto de vista gerencial, as observações diretas realizadas na pesquisa de campo revelaram que o impacto destes custos na empresa é uma questão chave para as tomadas de decisões. A renovação de frotas representa investimentos elevados. Com relação com as melhores práticas de gestão da manutenção para se tornar no futuro uma Manutenção Classe Mundial (World Class Maintenance), a empresa estudada precisa ainda avançar mais, podemos considerar que a empresa tem as 
seguintes ferramentas já implantadas na manutenção: Os Indicadores de desempenho, 5S, Sistemas de Gerenciamento da Manutenção, alguns pilares da TPM, e falta investir em ferramentas como: Confiabilidade e RCM - Manutenção Centrada em Confiabilidade, Manutenção Preditiva, g) Lubrificação Avançada, Benchamarking Indicadores e Melhores Práticas Manutenção e Planejamento Estratégico Manutenção.

Também a empresa pesquisada precisa fazer investimentos em alinhamentos e balanceamentos para evitar os desgastes prematuros, além de um bom programa gerenciador de pneus, para controle de pressão dos pneus sobre a frota, cálculos e relatórios sobre o $\mathrm{CPK}$ dos pneus e também realizar treinamentos eficazes para os colaboradores envolvidos nas operações (motoristas, encarregados da triagem e da expedição, lideres e gestores).

Foi observado que se caso esses investimentos não ocorressem, a perda dos pneus da frota seria em mais $10 \%$ do consumo de borracha de todos os pneus para a frota completa. Por exemplo, ao calcular isto na empresa de estudo, o valor médio dos pneus da frota era de $R \$ 750,00$ e a média de $\mathrm{mm}$ de cada pneu da frota é de $10 \mathrm{~mm}$, sendo o preço de cada $\mathrm{mm}$ do pneu $\mathrm{R} \$ 75,00$. Os números de pneus da frota era de 5.800. Portanto, obtém um resultado de $R \$ 4.350 .000,00(5800 \times 75,00 \times 10)$, que é igual a uma perda de $\mathrm{R} \$ 435.000,00$ (10\%), o que representa aproximadamente uma perda 362 pneus.

Outro ponto relevante apurado na gestão de pneus feita neste estudo, com relação a compras de pneus na área de manutenção (setor de compras), apurou-se que as compras mensais (pneus novos) de 100 pneus mês eram feitos compras na revenda, com um custo de aproximadamente $30 \%$ superior ao preço de fábrica, que depois deste trabalho à empresa passou a comprar diretamente da fábrica, reduzindo seus custos na compra do total de 100 pneus, quase 30 pneus eram ganho por mês na redução destes preços de compra, ou seja, em um ano a empresa compra 1200 pneus, a empresa começou a economizar 360 pneus por ano, ou seja, (360 pneus $x \mathrm{R} \$$ $1.200,00=432 \cdot 000,00)$.

Portanto somando (consumo e compra) uma perda não percebida na gestão de pneus neste estudo de caso pode observar que a empresa perda em torno de $\mathrm{R} \$$ 
$867.000,00$ por ano, ou seja, 722 pneus anuais a preço de mercado em sua gestão de pneus. Neste caso o custo de pneus novos mensais no custo da manutenção mensal seria de $15,20 \%$, ou o dobro encontrado na parte teórica que seria de no máximo de $8 \%$ no custo total.

As questões de pesquisa um e dois (Q1 e Q2) formuladas na introdução: foram respondidas na coleta dos dados qualitativos, conforme síntese da Figura 2. O conceito de manutenção na gestão de pneus foi fundamentado por 8 práticas e o conceito de desempenho por 10 indicadores (Figura 2). A pesquisa qualitativa também revelou que a falta do comprometimento dos envolvidos nas áreas operacionais influenciam na gestão de manutenção e pneus.

Já na análise quantitativa, a questão 3 (Q3) desta pesquisa foi respondida pela análise de correlação de Pearson, conforme Tabela 2. As variáveis associadas positiva e significativamente aos custos aplicados aos pneus foram: o número de ordens de serviço, custo total de manutenção, número de pneus sucateados e número de veículos calibrados.

Os resultados da análise de regressão simples revelaram que $54 \%$ da variação nos custos totais de manutenção dizem respeito aos custos aplicados aos pneus (análise de regressão simples) e 65\% da variação nos custos totais da manutenção dizem respeito a três variáveis conjuntamente: custos aplicados aos pneus, número de veículos calibrados e custos com pneus nas estradas Estes resultados respondem a questão quatro (Q4) deste trabalho.

Os resultados desta análise de perdas são altamente significativos, para melhor visualizar esta análise precisamos saber desta dimensão desta frota deste estudo, o quanto ela roda por mês, em: a) números de veículos, b) números de pneus, c) medidas de pneus, d) marcas de pneus, e) modelos de pneus, f) principais reformadores, g) principais desenhos de reforma, $h$ ) apurados descritos abaixo:

- Números de veículos da frota apurados 490 (Volvo, Scania, Mercedes, Iveco, para os cavalos e Randon, Librelato, América e Fachini para as carretas); 
- Números de pneus rodando: da dianteira -312; tração 504; lisos truck e carretas, - 4784 pneus;

- Os tipos de veículos são: carretas 03 eixos - 32,99\%; tanques GLP $14,46 \%$, cavalos $6 \times 4$ - 12,83\% e 4x2 - 9,16\%; truck - 11\%; prancha - 9,16\%, carretas sider $-3,26 \%$ e bug - $1,02 \%$;

- Medidas de pneus 29580R22,5 - 70,03\%; 1100R22 - 20,98\%; 27580R22,5 2,74\%; 1000R-20 - 2,19\%; 27580R22,5 - 1,25\%; 275R22,5 - 0,57\%; $21575 R 22,5-0,35 \%$ e outros $1,09 \%$;

- Marcas de pneus: Bridgestone - 34, 63\%; Goodyear - 33, 02\%; Michelin 29, 67\%; Firestone - 1\%; Kumho - 0,78\%; Pirelli 0,39\% e outros - $0,51 \%$;

- Modelos de pneus: Bridgestone R 250 - 39,14\%; Goodyear - G 359 26,46\%; Michelin XZE2+ - 20, 12\%; Pirelli FR $25-2,6 \%$; outros - 11,67\%;

- Principais reformadores: Bandag (Unicap) - 55,87 \%; Tipler (Jardim) $42,83 \%$, Michelin - $0,87 \%$ e outros - $0,43 \%$;

- Principais desenhos de reforma: RT 61 (Tipler) - 40, $68 \%$; BTLSA2 (Bandag) - 31,84\%; BDR2SA (Bandag) - 22,41\%; XTE (Michelin) - 3,67\% e outros $-1,40 \%$.

A média geral do km percorrido apurado no período de 2009/2010/2011 foi de $1.457 .420 \mathrm{~km}$, as principais perdas levantadas em pneus foram: na dianteira, no estudo interno realizado na empresa os pneus rodam em média $85.000 \mathrm{~km}$ e de tração $72.000 \mathrm{~km}$, (nota-se que os pneus furados, cortados e estourados são substituídos por outros, cada vez que isto ocorre fecha o $\mathrm{km}$ rodado do pneu, e é feito a ficha de controle para lançamento no sistema de controle de pneus).

A fórmula a ser utilizada para o cálculo do custo por quilometro rodado em pneus para veículos de transporte rodoviário de cargas para $n+1$ reformas são:

- Utilizar a primeira vida com posterior venda da carcaça;

$$
\mathrm{CF} 1=\frac{\mathrm{C} 0-(1 . \mathrm{P} 0) \times \mathrm{V} 0}{\mathrm{~K} 0}
$$

- Uso da primeira vida mais uma reforma e posterior venda da cacaça;

Revista Produção Online, Florianópolis, SC, v.14, n. 4, p.1235-1269, out./dez. 2014. 


$$
\mathrm{CF} 2=\frac{(\mathrm{CO}+\mathrm{CR}) \cdot(1 \cdot \mathrm{P} 1) \times(\mathrm{V} 1)}{(\mathrm{K} 0+\mathrm{K} 1)}
$$

- Uso da primeira vida mais duas reformas e posterior venda da carcaça:

$$
\mathrm{CF} 3=\frac{(\mathrm{C} 0+2 \times \mathrm{CR}) \cdot(1 \cdot \mathrm{P} 2) \times \mathrm{V} 2}{(\mathrm{~K} 0+\mathrm{K} 1+\mathrm{K} 2)}
$$

Onde:

- $\mathrm{CF}$ - custo final do pneu;

- $\quad$ C0 - custo de aquisição do pneu novo;

- $\quad \mathrm{CR}$ - custo de recape;

- V0 - valor de venda da carcaça de primeira vida;

- V1 - valor de venda das carcaças após o primeiro recape;

- V2 - valor da venda das carcaças após o segundo recape;

- $\mathrm{KO}$ - quilometro percorrido pelo pneu na primeira vida;

- $\mathrm{K} 1$ - quilometro percorrido pelo pneu após o primeiro recape;

- K2- quilometro percorrido pelo pneu após o segundo recape;

- P0- índice de perda de pneus (sucateados) de primeira vida (sem possibilidades de venda);

- P1- índice de perdas de pneus (sucateados) após o primeiro recape (sem possibilidades de venda) - acumulado P0;

- P2- índice de perda de pneus (sucateados) após o segundo recape (sem possibilidades de venda) - acumulado P1.

As perdas podem ser medidas e mensuradas nas análises de sucata mensais dos pneus fora de uso, por avaliação de desgastes dos pneus, principalmente nos pneus novos de dianteira, tração e truck, e por inspeção de veículos realizados (onde realiza uma análise de prejuízos mensais e apresenta sugestões de melhoria de operação em redução de custos com pneus e operacionais.

As estimativas quando da compra de um pneu novo, espera-se que estes pneus podem rodem pelo menos $100.000 \mathrm{~km}$ na sua primeira vida (vida útil), ao preço de mercado na medida $29580 R 22,5$, e em torno de $R \$ 1100,00$, as empresas fazem 
geralmente um só alinhamento em toda a primeira vida útil do pneu, portanto utilizando a primeira fórmula;

$$
\mathrm{CF} 1=\frac{1100,00-(1.1) \times 200,00}{100.000 \mathrm{~km}}=\frac{1100,00-200,00}{100.000 \mathrm{~km} .}=0,0090(\text { Valor do CPK })
$$

$\mathrm{Na}$ análise de pneus novos (pneus dianteiros), portanto se a média da empresa gira em torno de $85.000 \mathrm{~km}$, o CPK dos pneus são:

$$
\mathrm{CF} 1=\frac{1100,00-(1.1) \times 200,00}{85 \cdot 000 \mathrm{~km}}=\frac{900}{85.000 \mathrm{~km}}=0,010 \mathrm{de} \mathrm{CPK}
$$

Da condição de compra para a situação de uso, o CPK variou de 0,009 para 0,010 ou seja $10 \%$, multiplicando pelos números de pneus da dianteira da empresa de estudo (312), vezes o valor de pneu de mercado $R \$ 1.100,00$ cujo resultado é $R \$$ $343.200,00$, estimando a perda apurada de 10\% (média apurada do CPK) a empresa perdeu em desempenho dos pneus, para efetuar somente um alinhamento e um balanceamento em toda a primeira vida destes pneus $R \$ 34.320,00$ reais.

Para os 504 pneus de tração, a empresa não compra pneus novos para a reposição dos mesmos, usa somente pneus ressolados (borrachudos) gerados da primeira vida dos pneus da dianteira e outras carcaças novas, vindo de outros segmentos como tanques, pranchas, cargas secas, girando em torno da média de $72.000 \mathrm{~km}$, e utiliza pneus novos somente da compra de veículos novos.

Já para calcular perda total de pneus frota foi feito uma inspeção em veículos, realizado pela recuperadora de pneus (Bandag - Unicap), junto com a empresa, onde foram inspecionados 197 pneus da frota que representou um amostra de 4,11\% deste total de pneus da empresa, sendo que nesta amostra foram: 16 (frente), 32 tracionais (tração) e 149 livres ( maioria dos pneus da empresa num total de 4862), onde foi constatado quanto a profundidade de sulcos: a faixa de remoção - 10 pneus (5\%); na faixa de alerta (30\%); acima do sulco de remoção: 8 pneus (4\%); acima da faixa de alerta: 179 pneus (91\%), e a pressão de ar: não verificada foi de $10(5 \%)$, muito baixa 
39 (20\%), pressão baixa 70 (36\%), pressão normal 53 (27\%) e pressão alta $25(13 \%)$, quanto a emparelhamento 164 (83\%), desemparelhados 32 (16\%), não verificados 1 (1\%), quantos as laudos de inspeção - pneus: corrigir pressão 60 (30\%), desemparelhados $23(12 \%)$, pressão de ar não revisada 20 (10\%), paralelismo entre eixo 19 (10\%) e falta de tampinha de válvula $18(9 \%)$.

Analisando o total de prejuízo projetado através do programa Survey da Bandag Unicap destra amostra para a frota, no ciclo de vida dos pneus aplicados foram descritos na Tabela 6.

Tabela 6 - Total do prejuízo projetado

\begin{tabular}{clc}
\hline Prejuízos potenciais & Remanescentes & Original \\
\hline Desgastes por pressão correta & $\mathrm{R} \$ 110.772,84$ & $\mathrm{R} \$ 237.180,76$ \\
Desgastes por desemparelhamento & $\mathrm{R} \$ 23.248,44$ & $\mathrm{R} \$ 69.240,24$ \\
Desgastes Irregulares & $\mathrm{R} \$ 14.950,48$ & $\mathrm{R} \$ 152.336,31$ \\
Perdas de carcaça & $\mathrm{R} \$ 67.884,33$ & $\mathrm{R} \$ 67.884,33$ \\
Socorros em estradas & $\mathrm{R} \$ 6.806,38$ & $\mathrm{R} \$ 6.806,38$ \\
Total & $\mathrm{R} \$ 223.612,47$ & $\mathrm{R} \$ 533.448,02$ \\
\hline
\end{tabular}

Portanto, confirma-se à hipótese de quanto maiores forem os custos aplicados aos pneus, maiores serão os custos totais da manutenção. $\mathrm{Na}$ análise estatística esta hipótese foi comprovada pelos coeficientes de correlação positivo e significativo entre essas duas variáveis de 0,73 e 0,66, conforme apresentados na análise de regressão simples e análise de regressão múltipla, respectivamente. Adicionalmente, pela soma dos prejuízos projetados nas análises anteriores, a análise de sucata de 2010 a 2011 teve um valor de $R \$ 141.196,02$; somando todas as perdas, isto resulta um prejuízo de $\mathrm{R} \$ 399.128,52$, ou seja, aproximadamente a perda de 362 pneus, baseados somente em três elementos dos assuntos pesquisados: alinhamento (desgastes), controle de pressão, análise de sucata (pneus fora de serviço).

\section{CONSIDERAÇÕES FINAIS}

Este estudo revelou o quanto os custos de pneus em um prestador de serviço logístico representam no custo da manutenção, também foram identificadas as práticas adotadas na empresa pesquisada e o que falta para implantar, conforme revisão 
teórica. O estudo também proporcionou melhorias para a empresa em estudo no que diz respeito à manutenção e gestão de pneus, revelando como os indicadores relacionados aos custos de pneus afetam o desempenho operacional da manutenção.

A partir das discussões apresentadas no transcorrer da pesquisa, verifica-se como a gestão de manutenção pode influenciar o percentual de tempo que os equipamentos estão disponíveis para a produção, que por sua vez, determina a saída alcançável e seu impacto na receita e nos custos.

Também revelam que o não comprometimento dos envolvidos nas áreas operacionais quanto aos seus processos, influenciam na área de manutenção e gestão de pneus.

Revelou-se também que dentre os indicadores de desempenho da manutenção na gestão de pneus, os custos aplicados aos pneus possuem maior correlação com o custo total da manutenção.

Foram destacados os conceitos sobre técnicas de manutenção específicas na gestão de pneus, além de identificar os indicadores de desempenho na área de gestão de pneus.

Assim, o presente trabalho contribuiu para um aperfeiçoamento dos conhecimentos e redução das lacunas nas áreas de gestão de frota, manutenção, pneus e indicadores de desempenho voltados a serviços de transportes.

$\mathrm{Na}$ revisão teórica na área de manutenção para gestão de pneus (HAVIARAS, 2005; LOCH, 2007) foi constato que pouco se sabia sobre práticas de manutenção, gestão de pneus e medição de desempenho conjuntamente. Estes estudos voltaram-se mais na manutenção como: desafios enfrentados, a qualificação de mão de obra, nível da informatização, a terceirização dos serviços, entre outros. Outros estudos como de Oliveira (2005), diziam respeito à análise de confiabilidade dos pneus radiais, analises de causas falhas com as medidas preventivas e relacionando a manutenção como um aspecto pontual.

Portanto, esse estudo contribuiu para complementar os estudos existentes, revelando as práticas desta área e em especial os indicadores de desempenho usados 
e seus referidos conceitos, além da relação entre esses indicadores por meio dos testes estatísticos.

A limitação do presente estudo refere-se apenas a pesquisa em uma só empresa e por esta razão os dados não podem ser generalizados. Portanto, uma das sugestões para futuros trabalhos é realizar uma pesquisa survey com várias empresas a fim de testar estes e outros indicadores utilizados para ampliar o estudo realizado. Seria interessante também que estudos futuros apresentassem e analisassem indicadores financeiros, voltados para estratégia, confrontando com a área de manutenção na gestão de pneus a fim de averiguar a influência destes sobre indicadores financeiros e não somente por indicadores operacionais.

A escolha deste tema de pesquisa justificou-se pela importância da logística no transporte de cargas, pelo modal rodoviário, e é neste cenário que a manutenção está inserida. Assim o presente trabalho contribui para um aperfeiçoamento dos conhecimentos nas áreas de gestão de frotas, manutenção, pneus e indicadores de desempenho voltados a serviços de transportes.

Este estudo proporcionou melhorias para a empresa, no que se diz respeito à manutenção e gestão de pneus, revelando como os indicadores relacionados aos custos de pneus afetam o desempenho operacional da manutenção. Também se acredita que o estudo contribui para o aperfeiçoamento do conhecimento sobre os temas apresentado neste trabalho, para os profissionais desta área e sugestões para futuros trabalhos a respeito deste estudo.

\section{REFERÊNCIAS}

AMBRÓSIO, C. W.; LEITE, M. S. A. Contratação por desempenho em serviços de manutenção: o caso da CTS Arcelor Brasil. Revista Produção-online, v.8, n. 3, 2008. http://dx.doi.org/10.14488/1676-1901.v8i3.130

ASSOCIAÇÃO NACIONAL DA INDÚSTRIA DE PNEUMÁTICOS - ANIP. Vendas de pneus para caminhões e ônibus no Brasil. São Paulo: ANIP, 2014.

BALLOU, R. H. Gerenciamento da cadeia de suprimentos. Porto Alegre: Bookman, 2001. 
BITITCI, U. S.; TURNER, T. J. The viable business structure for measurement agility. International Journal of Agile Management Systems, v.1, n.3, p.190-199, 1997. http://dx.doi.org/10.1108/14654659910296571

BRIDGESTONE BANDAG TIRE SOLUTIONS - BBTS. Centro de Treinamento Bandag Mercosul. Campinas (SP): BBTS, 2010.

CLEMENTE, Q. K. Gestão de frota de veículos rodoviários. Instituto Superior Técnica Universidade Técnica de Lisboa, Lisboa, Portugal, 2008.

COLLIS, J.; HUSSEY, R. Pesquisa em administração. Porto Alegre: Bookman, 2005.

CONFEDERAÇÃO NACIONAL DOS TRANSPORTES (CNT). Relatório analítico pesquisa empresa de cargas CNT. Disponível em:

http://www.cnt.org.br/Paginas/index.aspx, acesso em: 15 de fevereiro, 2010.

CONTRAM - Conselho Nacional de Trânsito (1980). Resolução n.ำ 558, de 15 de abril de 1980. Fabricação e reforma de pneumático com indicadores de profundidade. Brasília, DF.

CROSS, K. F.; LYNCH, R. L. The "SMART" way to define and sustain success. National Productivity Review, v.9, n.1, p.23-33, 1990.

DARIO, M. Práticas, indicadores e custos na gestão de pneus: estudo em uma empresa de transportes. (Mestre em administração). Mestrado Profissional em Administração, Faculdade de Gestão e Negócios, Universidade Metodista de Piracicaba, Piracicaba, 2012. $104 \mathrm{p}$.

DE TONI, A.; TONCHIA, S. Performance measurement systems models, characteristics and measures. International Journal of Operations \& Production Management, v.21, n.1-2, p.46-70, 2001. http://dx.doi.org/10.1108/01443570110358459

ESPOSTO, K. F. Elementos estruturais para a gestão de desempenho em ambientes de produção enxuta. Departamento de Engenharia de Produção, Escola de Engenharia de São Carlos da Universidade de São Paulo, São Paulo, 2008.

FLEURY, P. F. Gestão estratégica do transporte. Artigos Cel-Coppead/UFRJ. Disponível em: disponível em: http://www.cel-coppead.com.br, acesso em: acessado em: 19 de fevereiro de 2004, 2002.

FUNDAÇÃO ADOLPHO BÓSIO DE EDUCAÇÃO NO TRANSPORTE - FABET. O desafio está de volta. Revista melhor motorista de caminhão do Brasil. Disponível em: http://www.melhormotorista.com.br, acesso em: 15 de novembro, 2010.

GOODYEAR. Boletim de orientação técnica Goodyear. Revista O Carreteiro v.429, n.10, 2010. 
HAIR JÚNIOR, J. F., ANDERSON, R. E., TATHAM, R. L., et al. Multivariate data analysis. Upper Saddle River: Prentice Hall, 2005.

HAVIARAS, G. J. Metodologia para análise de confiabilidade de pneus radiais em frota de caminhões de longa distância. (Mestrado Profissionalizante em Engenharia Automotiva). Escola Politécnica Universidade de São Paulo, São Paulo, 2005. 128 p.

HRONEC, S. Vital signs: using quality, time, and cost performance measurements to chart your company's future. USA: Arthur Andersen, 1994.

KAPLAN, R. S.; NORTON, D. P. The balanced scorecard: mensures that drive performance. Harvard Business Review, v.70, n.1, p.71-79, 1992.

KARDECH, A. P.; NASCIF, J. Manutenção função estratégica. Rio de Janeiro: Qualtitymark, 2001.

KARDECH, A. P.; NASCIF, J. Manutenção função estratégica. 4ํㅡㄹ Edição, Rio de Janeiro: Qualitymark, 2013.

KATO, J. M. Cenários estratégicos para o transporte rodoviário de cargas no brasil. Departamento de Engenharia de Produção, Universidade Federal de Santa Catarina, Florianópolis, 2005. 167 p.

LAMBERT, D. M., EMMELHAINZ, M. A.; GARDNER, J. T. Developing and implementing supply chain partnerships. The International Journal of Logistics Management, v.7, n.2, p.1-17, 1996. http://dx.doi.org/10.1108/09574099610805485

$\mathrm{LOCH}, \mathrm{C}$. A. Estudo da gestão da manutenção em uma empresa do segmento Logístico. (Grau de Engenheiro). Curso de Graduação em Engenharia, Habilitação em produção e sistemas, Universidade do Estado de Santa Catarina, Joinvile, 2007.

NARAYAN, V. How are safety, quality, reliability, productivity and maintenance related? Journal of Quality in Maintenance Engineering, v.18, n. 2, p.183-195, 2012. http://dx.doi.org/10.1108/13552511211244210

NEELY, A., GREGORY, M.; PLATTS, K. Performance measurement system design: A literature review and research agenda. International Journal of Operations \& Production Management, v.25, n.12, p.1228-1263, 2005.

http://dx.doi.org/10.1108/01443570510633639

NOVAES, A. G. Logística e gerenciamento da cadeia de distribuição. São Paulo: Campus, 2002.

OLIVEIRA, A. M. Pneus Automotivos, análise critica dos requisitos de segurança e de desempenho. (Mestrado Profissional em Engenharia Automotiva). Escola Politécnica, Universidade de São Paulo, São Paulo, 2005. 165 p. 
PERES, C. R. C.; LIMA, G.B.A. Proposta de modelo para controle de custos de manutenção com enfoque na aplicação de indicadores balanceados. Gestão e Produção. São Carlos, v. 15, n. 1, p. 149-158, jan.-abr. 2008.

SETCESP. Sindicato das Empresas de Transportes de Cargas do Estado de São Paulo. Manutenção de frotas no transporte. Disponível em:

<http://www.setecesp.org.br/curso.asp?id=733>, acesso em: 03/02/2009, 2009.

SINK, D. S.; TUTLE, T. C. Planejamento e medição para a performance. 1.ed. Rio de Janeiro: Qualitymark, 1985.

SOARES, R., MARÇAL, R. F. M.; SCANDELARI, L. Gerenciamento de pneus em frota de caminhões de carga. XVIII SIMPEP - Simpósio de Engenharia de Produção. Bauru (SP). 06 a 8 de novembro 2006.

SULTANA, M.; RAHMAN, A.; CHOWDHURY, S. A review of performance based maintenance of road infrastructure by contracting. International Journal of Productivity and Performance Management, v.62, n.3, p.276-292, 2013.

http://dx.doi.org/10.1108/17410401311309186

TOPAL, E.; RAMAZAN, S. A new MIP model for mine equipment scheduling by minimizing maintenance cost. European Journal of Operational Research, 1 december 2010, v.207, n.2, pp.1065-1071, 2010.

VALENTE, A. M. Um sistema de apoio a decisão para o planejamento de fretes e programação de frotas no transporte rodoviário de cargas. Departamento de Engenharia de Produção, Universidade Federal de S. Catarina, Florianópolis, 1994.172

VALENTE, A. M., PASSAGLIA, E.; NOVAES, A. G. Gerenciamento de transportes e frotas. São Paulo: Pioneira, 2003.

VIVALDINI, M.; PIRES, S. R. I. Operadores logísticos: integrando operações em cadeias de suprimento. São Paulo: Atlas, 2010.

YIN, R. K. Estudo de caso: planejamento e métodos. Porto Alegre: Bookman, v.4 ed., 2010.

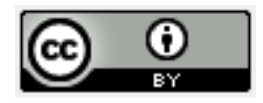

Artigo recebido em 14/09/2012 e aceito para publicação em 22/10/2014 DOI: http://dx.doi.org/ 10.14488/1676-1901.v14i4.1450 